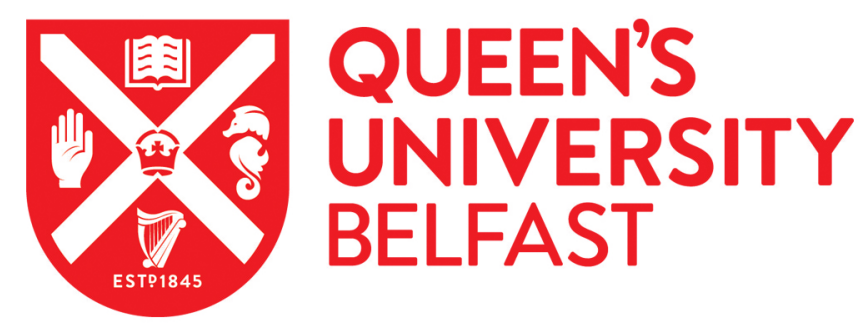

\title{
Does listening to music regulate negative affect in a stressful situation? Examining the effects of self-selected and researcher- selected music using both silent and active controls
}

Groarke, J. M., Groarke, A., Hogan, M. J., Costello, L., \& Lynch, D. (2019). Does listening to music regulate negative affect in a stressful situation? Examining the effects of self-selected and researcher-selected music using both silent and active controls. Applied Psychology: Health and Well-Being.

https://doi.org/10.1111/aphw.12185

Published in:

Applied Psychology: Health and Well-Being

Document Version:

Peer reviewed version

Queen's University Belfast - Research Portal:

Link to publication record in Queen's University Belfast Research Portal

\section{Publisher rights}

( 2018 The International Association of Applied Psychology. This work is made available online in accordance with the publisher's policies. Please refer to any applicable terms of use of the publisher.

\section{General rights}

Copyright for the publications made accessible via the Queen's University Belfast Research Portal is retained by the author(s) and / or other copyright owners and it is a condition of accessing these publications that users recognise and abide by the legal requirements associated with these rights.

Take down policy

The Research Portal is Queen's institutional repository that provides access to Queen's research output. Every effort has been made to ensure that content in the Research Portal does not infringe any person's rights, or applicable UK laws. If you discover content in the

Research Portal that you believe breaches copyright or violates any law, please contact openaccess@qub.ac.uk. 


\begin{abstract}

\section{Background}

Stress and anxiety is increasingly common among young people. The current research describes two studies comparing the effects of self-selected and researcher-selected music on induced negative affect (state anxiety and physiological arousal), and state mindfulness.

\section{Method}

In Study 1, 70 undergraduates were randomly assigned to one of three conditions: researcherselected music, self-selected music, or a silent control condition. In Study 2, with 75 undergraduates, effects of music were compared to an active control (listening to a radio show). Negative affect was induced using a speech preparation and arithmetic task, followed by music listening or control. Self-reported anxiety and blood pressure were measured at baseline, postinduction, and post-intervention. Study 2 included state mindfulness as a dependent measure.

\section{Results}

Study 1 indicated that participants who listened to music (self-selected and researcher-selected) reported significantly greater anxiety reduction than participants in the silent control condition. Music did not reduce anxiety compared to an active control in Study 2. However, music listening significantly increased levels of state mindfulness, which predicted lower anxiety after selfselected music listening.

\title{
Conclusions
}

Music may provide regulation in preparation for stressful events. Yet, the results of Study 2 indicate other activities have similar benefits, and shows, for the first time, that music listening increases mindfulness following a stressor.

Keywords: Anxiety, Stress, Coping, Regulation, Music listening, Mindfulness 


\section{Introduction}

The prevalence of stress and anxiety today, particularly in young populations, is of growing concern. In Ireland, almost a third of University students report psychological difficulties and over a quarter drop out of study due to stress (Higher Education Authority, 2018). Chronic exposure to stress and anxiety can contribute to a range of psychological and physical health problems such as depression, high blood-pressure, and an increased vulnerability to illness (Cohen, 1991). The need for easily accessible, cost-effective interventions for stress management and affect regulation in student populations is thus an imperative.

\section{Music and Regulation}

Music listening is increasingly recognised as a potentially effective method of stress, mood, and emotion regulation (Baltazar \& Saarikallio, 2019). Affect regulation is often considered to be the most important function of music listening (Juslin \& Sloboda 2001) and participants who endorse using music listening for affect regulation have been found to report higher wellbeing in a number of studies (Groarke \& Hogan, 2018). A meta-analysis of 22 experimental studies demonstrated that music listening significantly decreased arousal due to stress (Pelletier 2004). A more recent meta-analysis of 19 randomised controlled trials reported a significant effect of music listening on self-reported anxiety in healthy adults (Panteleeva, Ceschi, Glowinski, Courvoisier \& Grandjean, 2018). Given that students listen to music for up to four hours a day (Lonsdale \& North, 2011) it could prove useful as an accessible everyday intervention for the regulation of stress and anxiety in this group.

Affective experience is a multi-component process encompassing moods, emotions and stress (Scherer, 1984), and includes both a valence component (i.e., positive to negative affect) and an arousal component (i.e., high to low arousal; Russell, 1980). Although experientially 
distinct, stress, anxiety, worry, and tension can be categorised as negatively-valenced and higharousal affective states.

A large body of research has focused on demonstrating how different types of music influence both cognitive evaluations of valence and physiological indicators of arousal (e.g., blood pressure, heart rate, cortisol). For example, in a within-subjects experiment by Iwanaga and Moroki (1999) participants reported greater relaxation and less tension after listening to slow tempo versus faster tempo music. Heart rate and systolic blood pressure (SBP) were significantly higher during faster music. The current study will examine the effect of music on both subjective evaluations of negative affect (i.e., state anxiety) and physiological indicators of arousal (i.e., blood pressure) following a stressor.

In the current study, a state of negative affect (NA) was induced in participants using an adapted version of The Trier Social Stress Test (TSST; Kirschbaum, Pirke, \& Hellhammer, 1993). The TSST is a widely used paradigm using speech preparation, public speaking, and arithmetic challenge to induce acute stress in laboratory settings. The TSST has been applied in previous studies on the regulating effects of music (Khalfa, Dalla Bella, Roy, Peretz \& Lupien, 2003). Adapted versions of the TSST protocol have also been used to examine music listening effects on stress-related outcomes (de la Torre-Luque, Diaz-Petra, \& Buela-Casal, 2017). Other laboratory studies of music have used a variety of protocols that are very similar to the TSST, using a combination of a speech preparation task (without public speaking) and a cognitive challenge (e.g., Scheufele, 2000; Knight \& Rickard, 2001), the prospect of performing a cognitive challenge only (Burns, Labbé, Williams, \& McCall, 1999), or cognitive challenge with harassment (Radstaak, Geurts, Brosschot, \& Kompier, 2014). In the current study, music listening occurs after the introduction of the stressor (i.e., speech preparation and an arithmetic 
challenge), but prior to giving the anticipated speech. This design permits an examination of whether music listening has a regulatory effect on NA induced by a stressor in preparation for a further stressful situation.

While the majority of experimental studies on music listening have used researcherselected relaxing classical music, it has been argued that self-selected music may be a particularly successful tool for regulation (Burns et al., 1999). Thaut and Davis (1993) conducted one of the first studies to demonstrate the increased efficacy of self-selected music in reducing subjective anxiety relative to researcher-selected music. Consistent with these results, Eerola and Vuoskoski (2013) urge researchers to choose ecologically valid stimuli in studies focused on music and emotion. Notably, classical music listening is infrequent in younger age groups (North, Hargreaves, \& Hargreaves, 2004). Therefore, a focus on classical music does not represent the typical music listening experience of young adults, and this may make it difficult to generalise findings emerging from studies of affect regulation that prescribe classical music as a means of supporting regulation.

At the same time, the majority of studies examining the effects of self-selected musical stimuli have required participants' choices to meet certain criteria, such as music which is relaxing or stimulating (Burns et al., 1999). Constraining musical selection in this way may limit the ecological validity of these studies, as the music that people engage with on an everyday basis may not be selected in such restrictive ways (Schäfer \& Sedmeier, 2009). For example, Nater, Abbruzzesse, Krebs and Ehlert. (2006) found that compared to classical music, heavy metal, a genre of music popular with younger adults, produced a state of negative affect in participants in a laboratory setting. However, Sharman and Dingle (2015) found that for fans of heavy metal music, exposure to this music after an anger induction led to increased relaxation 
and stabilisation of self-reported negative affect (NA) compared to those in a silent control condition. North and Hargreaves (2000) found that participants who had been assigned to an aerobics class selected high arousal music, while participants in a relaxation group chose low arousal music. However, following exercise, participants had a preference for low arousal music. These findings indicate that arousal regulation for different functions is an important consideration in music selection. Everyday music listening experiences may be influenced by the context within which the music listening is occurring, personal music preferences, and the key functions of music listening a person is pursuing. Therefore, a more ecologically valid approach to experimental research would be to employ self-selected music based on function and context, for example, asking participants to select preferred music for a stressful or social situation or for motivational contexts.

Another challenge in interpreting previous research on the effect of music listening is that most studies have used only one control group, namely, rest with no acoustic stimulation. Studies that have experimentally induced stress or negative affect in the laboratory also show an overreliance on silent control conditions (e.g., Knight \& Rickard, 2001; Sandstrom \& Russo, 2010). It is unclear from these studies whether the positive effects of music on affect regulation is due to the music itself or differences in participant arousal. For example, the studies by Khalfa et al. (2003) and Knight \& Rickard (2001) showed that participant cortisol levels increased in silent conditions, suggesting it may be perceived as stressful. The inclusion of active control conditions provides an alternative way of examining the effects of music listening on select outcomes.

A study by Nantais and Schellenberg (1999) showed that when an active control (i.e., audiobook listening) was introduced the previously reported cognitive benefit (or 'Mozart 
Effect'; Rauscher, Shaw \& Ky, 1993) of a music listening intervention on spatial tasks was no longer found, suggesting that the music intervention may only be successful when compared to a silent control condition. However, other studies using a non-musical control have found music listening to be more beneficial following a stress induction than white noise (Sandstrom \& Russo 2010)or a cognitive reframing writing task (Sleigh \& McElroy, 2014) following a sadness induction.

However, like silence, white noise and writing tasks could also be considered aversive and stressful by participants and potentially confound effects in favour of music listening. Chanda and Levitin (2013) recommend an active control condition that may provide similar rewards as music in terms of level of arousal, attentional capture, and affective engagement (e.g., watching television or reading). Comparable activities in the auditory domain might include listening to audiobooks, narrated text, or talk radio (e.g., Radstaak et al., 2014). There are few experimental studies focused on music and affect regulation that have adopted this methodological approach.

\section{Music and Mindfulness}

While much evidence to date indicates that music listening can regulate affective experiences, the mechanisms of regulation are not fully understood. Potential mechanisms include rhythmic entrainment, episodic memory, and aesthetic judgement, as well as, regulation strategies, such as, reappraisal, distraction, and rumination (Baltazar \& Saarikallio, 2019). Indeed, distraction is one of the most commonly used strategies in music listening (Van Goethem \& Sloboda, 2011), outside of music research distraction and reappraisal are considered the most effective strategies for reducing NA (Augustine \& Hemenover, 2007). In contrast, rumination is consistently associated with the maintenance of NA (Nolen-Hoeksema, 1991). Another possible regulation strategy that has received little attention is increased mindfulness. Mindfulness is 
defined as the purposeful and non-judgemental awareness of the present moment, including the transient nature of thoughts, feelings and sensation (Kabat-Zinn, 2003). Mindfulness-based stress reduction programmes reduce stress and anxiety, and are thought to do so by reducing reactivity and rumination (Goldin \& Gross, 2010). Broderick (2005) found that following an NA induction, a brief mindfulness intervention reduced NA more than distraction and rumination instructions. Studies comparing the relative efficacy of mindfulness and distraction on regulation have been less conclusive (Keng, Smoski \& Robins, 2011). One study of university students found that higher levels of self-reported mindfulness was associated with lower perceived stress and higher levels of adaptive coping (Palmer \& Rodger, 2009). The review by Keng et al. (2011) concludes that mindfulness reduces reactivity, improves regulation, and increases wellbeing.

Direct evidence linking music with mindfulness is limited. One recent study by Lynch and Wilson (2018) showed that state-mindfulness increased significantly following a choir rehearsal, and to a lesser extent in the active control condition (i.e., 30 minutes of listening to classical choral music at home). The structure of music is often highly predictable, including regular and cyclical rhythmic patterns (Juslin \& Sloboda, 2001) akin to the regular and cyclical nature of breathing. These regular and cyclical rhythmic patterns may be supportive of increased mindfulness, particularly the present-moment focus on a specific sensory experience, which is often a feature of mindfulness practices that focus on the breath (Kabat-Zinn, 2003). While no study has examined music listening as a means of enhancing both mindfulness and anxiety regulation in stressful situations, similar to mindfulness states, a number of studies have found that flow states, intense emotional experiences, and absorption are a key feature of the music listening experience (Gabrielsson, 2010). According to a theoretical model put forward by Schäfer, Smukalla, and Oelker (2014) these features of musical experiences facilitate mood 
improvements and cognitive restructuring that in turn support enhanced wellbeing. State mindfulness may increase as a result of listening to music, and mindfulness may support coping with stressors. However, no study has examined the efficacy of music listening as a tool for increasing mindfulness in response to a stressor.

\section{Aims of the Study}

The current research, comprising two studies, builds upon previous experimental work in music listening and affect regulation by incorporating a stress induction, the use of participant-selected music stimuli, an active control condition, and it explores for the first time the link between music listening and state mindfulness following a stressor. The role that mindfulness may play in musical affect regulation is also examined. Employing self-selected music in laboratory-based studies has the benefit of increasing ecological validity, as in everyday contexts people select their own music for the function of affect regulation (Schäfer \& Sedlemeir, 2009).

Consistent with research findings on the benefits of self-selected music in supporting affect regulation (Burns et al., 1999;), and research indicating the relative efficacy of selfselected music in reducing anxiety when compared to researcher-selected music (Thaut \& Davis, 1993), Study 1 hypothesised that following a stress induction individuals listening to music would experience greater reduction of negative affect than individuals in a silent control condition, and that negative affect reduction would be greatest in the self-selected music listening condition relative to researcher-selected music. Study 2 examined the same hypotheses while employing further methodological controls in the form of an active control condition (listening to a radio show). Study 2 also posited that individuals in the music conditions would experience higher levels of mindfulness than individuals in the active control condition. 


\section{Method}

This study was conducted according to the principles expressed in the Declaration of Helsinki. All procedures were reviewed and approved by the School of Psychology, Research Ethics Committee at the National University of Ireland, Galway.

\section{Design}

Both studies employ a repeated measures between-subjects design. The independent variable in Study 1 was condition (researcher-selected music, self-selected music, silent control) while the dependent variables were self-reported anxiety, and blood pressure. Study 2 using the same design further investigated the efficacy of the researcher-selected music and self-selected music interventions using an active control and added the dependent variable of state mindfulness. All dependent measures in both studies were recorded at three time points: baseline, post-induction, and post-intervention.

\section{Participants}

Undergraduate students with normal or corrected-to-normal vision and hearing who were over the age of 18 years were eligible to take part (or aged 17 with parental consent). Due to the stressful nature of the study participants diagnosed with a psychological disorder (i.e., depression, anxiety, PTSD) were not eligible to take part. Participants received course credits for participation in the study. Study 1 had 70 participants ranging in age from 17 to 53 years old (M $=20.50, \mathrm{SD}=4.77: 17$ males; 53 females). Study 2 had 75 participants ranging from age 17 to 34 years old $(\mathrm{M}=20.23 \mathrm{SD}=3.14 ; 19$ males; 56 females $)$.

In accordance with previous studies of musical affect regulation (Radstaak et al., 2014), smallmedium effect sizes were expected and two-tailed alpha of .05 was assumed for all tests. In 
particular, it was estimated in G-power that a sample of at least 70 participants was needed to identify an effect size of $d=0.2$ in the context of power $=0.80$.

\section{Procedure}

Participants were recruited via a university research recruitment online system. Deception was used in this research in order to control for expectation effects and demand characteristics. Specifically, participants were informed that the study was examining the effect of musiclistening on task performance. Participants completed an online pre-screen questionnaire where they provided demographic information, 10 minutes of their preferred music in a stressful and a social situation. Participants were tested individually. On the day of the study participants were required to refrain from smoking, caffeine and rigorous exercise one hour prior to the study. Upon arrival to the laboratory, participants were randomly assigned to condition using a random number generator. A participant information sheet was provided and written consent obtained. At baseline participant blood pressure, subjective anxiety and (in the case of Study 2) statemindfulness levels were recorded. Participants then underwent the stress induction (see description below). Physiological and psychological responses were recorded following the stress induction, and again 8 minutes later, after participants were engaged in music listening (self-selected or researcher-selected) or a silent (study 1) or active control (study 2) condition. Participants were then given a full debrief and retrospective written consent was sought. A diagrammatic illustration of the procedure is presented as supporting information.

\section{Materials and Apparatus}

Audio was played via PC through SONY over-ear headphones. Each participant selected a volume that was comfortable for them. 
Researcher-Selected Music. The song "Weightless" by Macaroni Union was used as the researcher-selected music for both studies. Researchers from the British Academy of Sound Therapy collaborated with the band Macaroni Union to create the "most relaxing song in the world". The song has no repeating melody and progressively slows from 60 beats per minute (BPM) to 50 BPM over its' 8-minute duration.

Self-selected Music. Participants provided 10 minutes of their preferred music for both a stressful and a social situation (i.e., song title, artist, genre).

Active control. A radio documentary entitled "A New Take on Darwin's Origin of Species” from the radio show "Talk of the Nation" was played as an active-control in Study 2.

The Trier Social Stress Test. The TSST (Kirschbaum, Pirke \& Hellhammer, 1993) was employed in both studies in order to induce mild-moderate psychosocial stress. The TSST is one of the most frequently used laboratory protocols for stress induction and is considered a highly reliable method. Participants are told to imagine they are invited to a job interview and that they must prepare a speech that will be recorded for subsequent analysis. The TSST has three phases: a speech preparation phase, a free speech phase where they describe why they are the best candidate for the job, and a mental arithmetic task (counting backwards from 2023 in steps of 17 aloud). Many aspects of the TSST can be modified to meet the needs of various research programs (Birkett, 2011). In the current study the TSST was modified in that participants never gave the speech but were not informed of this until debriefing (i.e., after the music/control condition). There was a 5-minute speech preparation phase, followed by the 3-minute mental arithmetic task prior to the application of music/control conditions.

The State-Trait Anxiety Inventory (STAI; Spielberger, 2010). A state-only version of the STAI was used to measure subjective anxiety in both studies. The STAI is made up of 20 statements, 
such as, "I am worried". Participants rate their level of agreement on a 4-point Likert scale from "Not at All" to "Very Much So". Scores range from 20-80; higher scores indicate greater anxiety.

The State Mindfulness Scale (SMS; Tanay \& Bernstein, 2013) was employed in Study 2. The SMS is a 21-item self-report questionnaire comprising of two components, state-mindfulness of bodily sensations, and state-mindfulness of mental events. Participants answer statements relating to their awareness of their present moment experiences on a 5-point Likert-scale ranging from "Not True at All" to "Very True". Scores can range from 21 to 105. Higher scores indicate higher levels of state-mindfulness.

Physiological arousal. Measures of physiological arousal were systolic and diastolic blood pressure, which were monitored by a blood pressure machine (Dinamap PRO, model 100V2) and standard blood pressure cuff. Participants were seated with feet flat, legs uncrossed, and their back and arm supported. The cuff was placed on the left arm at heart level. Measures of BP were taken at baseline (after a 10 minute waiting period), post-induction (immediately after arithmetic task), and post-intervention (immediately after music listening/control).

\section{Results}

A series of 3 (condition: self-selected music, research-selected music, silent/active control) $\times 3$ (time: baseline, post-induction, post-intervention) mixed ANOVAs were conducted to examine differences in affect (self-reported anxiety and blood pressure) in studies 1 and 2, and statemindfulness in study 2 only. 


\section{Study 1}

\section{Self-reported anxiety (STAI)}

The results of a 3x3 ANOVA revealed a main effect of time $\left(F_{(2,134)}=66.02, p<.001, \eta_{\mathrm{p}}{ }^{2}=\right.$ $.496,90 \%$ CI $[.393, .567])$. There was no main effect for condition $\left(F_{(2,67)}=.95, p=.39\right)$. There was a significant interaction effect $\left(F_{(4,134)}=4.65, p=.002, \eta_{\mathrm{p}}{ }^{2}=.122,90 \%\right.$ CI $\left.[.031, .190]\right)$. ---Insert Figure 1 about here ------Insert Table 1 about here --To investigate the significant interaction, follow-up one-way ANOVAs were conducted. There was no significant difference between conditions at baseline $\left(F_{(2,67)}=.35, p=.707\right)$ or postinduction $\left(F_{(2,67)}=.28, \mathrm{p}=.76\right)$. There was significant group differences in state anxiety postintervention $\left(F_{(2,67)}=5.99, p=.004, \eta_{\mathrm{p}}{ }^{2}=.152,90 \%\right.$ CI $\left.[.031, .267]\right)$. Post-hoc Tukey's HSD test revealed a significant difference between the self-selected music listening condition and the silent control condition $(p=.007$, Mean Difference $(M D)=8.63,95 \%$ CI $[2.07,15.20])$ with a large effect size $(d=.920,95 \%$ CI $[.312,1.52])$, and between the researcher-selected music listening condition and the silent control $(p=.017, \mathrm{MD}=8.63,95 \% \mathrm{CI}[1.19,14.46])$, also with a large effect size $(d=.834,95 \%$ CI $[.226,1.43])$. The difference between the self-selected music listening condition and the researcher-selected music listening condition was non-significant $(p=$ $.953)$.

There were also significant differences across timepoints in the self-selected music listening condition $\left(F_{(2,46)}=36.68, p<.001, \eta_{\mathrm{p}}{ }^{2}=.615,90 \%\right.$ CI $\left.[.444 ; .670]\right)$, the researcher-selected music listening condition $\left(F_{(2,44)}=21.13, \underline{p}<.001, \eta_{\mathrm{p}}{ }^{2}=490,90 \%\right.$ CI $\left.[.289, .601]\right)$, and the silent control condition $\left(F_{(2,44)}=19.45, p<.001, \eta_{\mathrm{p}}{ }^{2}=.469,90 \%\right.$ CI $\left.[.266, .584]\right)$. Pairwise comparisons with Bonferroni adjustment revealed that state anxiety was significantly higher 
post-induction than baseline with very large effect sizes for the self-selected music listening group $(p<.001, \mathrm{MD}=12.12,95 \% \mathrm{CI}[8.54,15.71], d=1.78,95 \% \mathrm{CI}[1.13,2.43])$, the researcher-selected music listening group $(p<.001, \mathrm{MD}=11.91,95 \% \mathrm{CI}=6.02,17.81], d=$ $1.0995 \%$ CI $[.564,1.60])$, and the silent control $(p<.001, \mathrm{MD}=12.00,95 \% \mathrm{CI}[6.47,17.53], d$ $=1.17,95 \% \mathrm{CI}[.631,1.70])$. State anxiety was significantly lower post-intervention than postinduction, with very large effect sizes for the self-selected music listening group $(p<.001, \mathrm{MD}=$ $-14.04,95 \%$ CI $[-18.96,-9.12], d=1.50,95 \%$ CI $[.908,2.08])$, and the researcher-selected music listening group $(p<.001, \mathrm{MD}=-10.87,95 \% \mathrm{CI}[-16.30,-5.44], d=1.08,95 \% \mathrm{CI}[.556,1.59])$. The means presented in Table 1 and Figure 1 show the magnitude of anxiety reduction was similar in both music listening conditions. In the silent control condition the reduction in state anxiety between post-induction and post-intervention was non-significant $(p=.077)$. For the music listening conditions there was no significant difference in state anxiety between baseline and post-intervention $(p=1.00)$. For those in the silent control condition state anxiety remained significantly higher than baseline levels $(p<.001, \mathrm{MD}=7.91,95 \% \mathrm{CI}[2.75,13.07])$, with a large effect size $(d=.828,95 \%$ CI $[.346,1.30])$.

\section{Physiological arousal}

\section{Systolic Blood Pressure}

The results from the $3 \times 3$ ANOVA showed that there was a main effect for time $\left(F_{(2,134)}=5.54\right.$, $\left.p=.005, \eta_{\mathrm{p}}{ }^{2}=.076,90 \% \mathrm{CI}[.014, .148]\right)$. Of all possible pairwise comparisons post-hoc Tukey's HSD tests revealed just one significant difference, specifically, that SBP was significantly lower post-intervention than at baseline $(p=.014, \mathrm{MD}=4.39,95 \% \mathrm{CI}[.697,7.88])$ with a small effect size $(d=.351,95 \%$ CI $[.108, .591])$. There was no main effect for condition $\left(F_{(2,67)}=.22, p=\right.$ 
$.80)$, and no interaction effect $\left(F_{(4,134)}=.31, p=.86\right)$.

\section{Diastolic Blood Pressure}

The $3 \times 3$ mixed ANOVA for DBP revealed no main effect for time $\left(F_{(2,134)}=.48, p=.62\right)$, or condition $\left(F_{(2,67)}=.19, p=.83\right)$, and no interaction $\operatorname{effect}\left(F_{(2,134)}=.25, p=.91\right)$.

\section{Study 2}

\section{Self-reported anxiety (STAI)}

The 3x3 ANOVA showed a main effect for time $\left(F_{(2,144)}=73.6, p<.001, \eta_{\mathrm{p}}{ }^{2}=.505,90 \% \mathrm{CI}\right.$ $[.407 ; .575])$, with post-hoc Tukey's HSD tests showing significant differences in state anxiety between baseline and post-induction phases $(p<.001, \mathrm{MD}=11.49,95 \% \mathrm{CI}[9.19,13.80])$ with very large effect sizes $(d=1.41,95 \%$ CI $[1.09,1.73])$. State anxiety post-intervention was significantly lower than post-induction $(p<.001, \mathrm{MD}=-10.05,95 \% \mathrm{CI}[-12.90,-7.21])$ with a large effect size $(d=.910,95 \%$ CI $[.720,1.27])$. There was no main effect of condition $\left(F_{(2,72)}=\right.$ $2.40, p=0.10)$ and no significant interaction $\operatorname{effect}\left(F_{(4,144)}=1.70, p=0.15\right)$.

\section{Physiological arousal}

\section{Systolic Blood Pressure}

The $3 \times 3$ ANOVA showed that there was a main effect for time $\left(F_{(2,144)}=3.56, p=0.03, \eta_{\mathrm{p}}{ }^{2}=\right.$ $.047,90 \%$ CI $[.002, .106])$, with SBP being significantly lower post-intervention than postinduction $(p=.016, \mathrm{MD}-3.05,95 \%$ CI $[-5.66,-.445])$ with a small effect size $(d=.331,95 \% \mathrm{CI}$ $[.098, .563])$. There was no main effect for condition $\left(F_{(2,72)}=0.20, p=0.82\right)$ and no significant interaction effect $\left(F_{(4,144)}=0.5, p=0.73\right)$.

\section{Diastolic Blood Pressure}

There was no main effect for time $\left(F_{(2,134)}=1.25, p=.29\right)$, or condition $\left(F_{(2,72)}=.66, p=.52\right.$, $)$, 
and no interaction effect $\left(F_{(4,144)}=1.33, p=.26\right)$..

\section{State Mindfulness}

The results from the $3 \times 3$ ANOVA revealed a main effect for time $\left(F_{(2,144)}=10.77, p<.001, \eta_{\mathrm{p}}^{2}\right.$ $=0.130,90 \% \mathrm{CI}[.050, .210])$. There was no main effect for condition $\left(F_{(2,72)}=0.90, p=0.41\right)$. There was a significant interaction effect $\left(F_{(4,144)}=3.15, p=0.02, \eta_{\mathrm{p}}{ }^{2}=.080,90 \%\right.$ CI [.009, $.137])$.

---Insert Table 2 about here ---

---Insert Figure 2 about here ---

To investigate the significant interaction follow-up one-way ANOVAs were conducted. There was no significant difference between conditions at baseline $\left(F_{(2,72)}=.39, p=.679\right)$, or postinduction $\left(F_{(2,72)}=.26, p=.772\right)$. There was significant between group differences in state mindfulness post-intervention $\left(F_{(2,72)}=4.26, p=.018, \eta_{\mathrm{p}}{ }^{2}=.110,90 \%\right.$ CI $\left.[.011, .210]\right)$. Post-hoc Tukey's HSD test revealed a significant difference between the researcher-selected music listening condition and the active control condition $(p=.021, \mathrm{MD}=11.00,95 \% \mathrm{CI}[1.37$, 20.64]) with a large effect size $(d=.772,95 \%$ CI $[.193,1.34])$. The difference in state mindfulness between the self-selected music listening condition and the active control postintervention was non-significant $(p=.068)$. The difference between the self-selected music listening condition and the researcher-selected music listening condition was also non-significant $(p=.887)$

There was no significant difference in state mindfulness between timepoints for the active control condition $\left(F_{(2,48)}=0.03, p=.968\right)$. There were significant differences across timepoints for the self-selected music listening condition $\left(F_{(2,48)}=8.46, p=.001, \eta_{\mathrm{p}}{ }^{2}=.261,90 \%\right.$ CI $[.082$, $.396])$ and the researcher-selected music listening condition $\left(F_{(2,48)}=8.66, p=.001, \eta_{\mathrm{p}}{ }^{2}=.265\right.$, 
$90 \%$ CI $[.085, .400])$. There was no significant difference in state mindfulness between baseline and post-induction in the self-selected music condition $(p=.411)$ or the researcher-selected music condition $(p=.393)$. State mindfulness was significantly higher post-intervention than post-induction with large effect sizes for both self-selected $(p=.002, \mathrm{MD}=11.48,95 \% \mathrm{CI}[3.98$, $18.98], d=.788,95 \% \mathrm{CI}[.331,1.23])$ and researcher-selected music $(p=.003, \mathrm{MD}=11.40$, $95 \%$ CI $[3.50,19.30], d=.742,95 \%$ CI $[.292,1.18])$. An examination of means in Table 2 and Figure 2 shows the greatest increase in mindfulness was in the researcher-selected music listening condition, followed by the self-selected music listening condition, and a (nonsignificant) reduction in mindfulness for those listening to a radio show (active control). Postintervention state mindfulness was significantly higher than baseline levels $(p=.041, \mathrm{MD}=$ $7.68,95 \%$ CI $[.263,15.10])$, with medium effect size $(d=.533,95 \%$ CI $[.108, .948])$ in the researcher-selected music listening condition, but not in the self-selected music listening condition $(p=.065)$.

\section{Moderation Analysis}

To examine if increased mindfulness supports affect regulation in the context of music listening, hierarchical regression analysis was performed using the SPSS macro PROCESS 3.3 (Hayes, 2017) for the 50 participants in the music listening conditions. Mindfulness increase was calculated as the difference in state mindfulness scores before and after music listening (selfselected music $M=11.48, S D=14.57$; researcher-selected music $M=11.40, S D=15.35)$. The overall model examining the effect of mindfulness increase $(\mathrm{X})$ on post-intervention anxiety $(\mathrm{Y})$ moderated by condition (M) was significant, with $29 \%$ of the variance in state anxiety postintervention explained by mindfulness increase, condition, and their interaction $\left(\mathrm{F}_{(3,46)}=6.37, p\right.$ $\left.=.001, r^{2}=.29\right)$. Mindfulness increase significantly predicted higher state anxiety after music 
listening (path $b_{1}, \mathrm{~B}=0.82, \mathrm{SE}=0.30, \mathrm{t}(46)=2.71, p=.009$ ). Music listening condition did not significantly predict state anxiety (path $b_{2}, \mathrm{~B}=2.13, \mathrm{SE}=3.63, \mathrm{t}(46)=.586, p=.561$ ). The interaction between mindfulness increase and condition (XM) significantly predicted lower state anxiety post-intervention (path $b_{3}, \mathrm{~B}=-0.678, \mathrm{SE}=0.19, \mathrm{t}(46)=-3.47, \mathrm{p}=.001$ ). The effects of mindfulness increase on state anxiety differed by condition. There was no relationship between mindfulness increase and anxiety in the researcher-selected music condition $(\mathrm{B}=.146, \mathrm{SE}=$ $.135, \mathrm{t}(46)=1.08, p=.283)$. For participants in the self-selected music condition, every 1 -unit increase in mindfulness reduced state anxiety by $.53(\mathrm{~B}=-.532, \mathrm{SE}=.142, \mathrm{t}(46)=-3.75, p<$ .001 ). Examination of the interaction plot (see Figure 3) shows a positive effect of increasing mindfulness on anxiety, but only in self-selected music listening.

---Insert Figure 3 about here---

\section{Discussion}

Two studies examined the impact of music on the regulation of subjective anxiety and physiological arousal in the context of ongoing negative affect due to the prospect of a stressful situation (i.e., giving a speech). Public speaking is a frequent challenge in academic life, and this research suggests that listening to music may support university students' adaptation to similar stressors. Another aim of the research was to compare the regulating effect of self-selected versus researcher-selected music against an active and a passive control. The hypothesis that participants listening to self-selected music would experience the greatest reduction in induced negative affect was partially supported. The hypothesis that individuals listening to music would experience higher levels of mindfulness than those in the active control (i.e., listening to a radio show) was supported. 


\section{Music and Regulation}

In both studies there was a significant increase in state anxiety following the introduction of the modified TSST, and a significant reduction in anxiety following music listening, with large to very large effect sizes. Consistent with previous research findings (Knight \& Rickard, 2001), Study 1 revealed that following the intervention anxiety was significantly lower in the music listening conditions when compared with the silent control condition, again with large effect sizes. These findings were also consistent with previous research demonstrating benefits of music on affect regulation before the cessation of a stressor (e.g., Knight \& Rickard, 2001; Sandstrom \& Russo, 2010). Furthermore, consistent with Study 1 hypotheses, the mean reduction in anxiety was largest in the self-selected music listening condition. This supports previous research findings showing benefits of self-selected music on regulation following a stressor (Radstaak et al., 2014). Previous studies have found greater benefits of self-selected music when compared with researcher-selected music (Burns et al., 1999; Thaut \& Davis, 1993). In the current study, state anxiety was significantly lower post-intervention for participants listening to music, but there was no significant difference in anxiety between self-selected and researcher selected music listening conditions. Findings here suggest that listening to music provides an effective means of regulating negative affect in times of stress, and that the music chosen by individuals for the function of affect regulation is as effective as music selected by researchers for its 'relaxing' properties (e.g., slow tempo).

It is interesting that the positive effects of music listening on anxiety were not apparent in Study 2 when music listening was compared with an active control. This is contrary to previous studies that did find significant regulatory effects of music relative to an active control (Radstaak et al., 2014; Sleigh \& McElroy, 2014). One could draw a parallel with findings from a series of 
studies that failed to replicate the 'Mozart effect' using control conditions other than silence (Nantais \& Schellenberg, 1999). One possible explanation for the lack of significant effects in Study 2 is that music listening and the active control provided similar levels of distraction and attentional capture (Chanda \& Levitin, 2013), thereby preventing rumination on the anticipated speech. In contrast, waiting in silence for an upcoming speech may have been more conducive to ruminating and, therefore, significantly less effective for affect regulation than music listening. In the series of investigations of the 'Mozart effect' mentioned above, cognitive effects were best explained as a test-performance artefact caused by the arousal and mood enhancing effects of different conditions. However, the potential impact of greater distraction, arousal, or positive mood effects of the active control condition was not explicitly measured in the current study, which makes this interpretation speculative but worthy of future investigation.

It is noteworthy that effects of music were observed on self-reported (subjective) anxiety and not on physiological measures of arousal in the current study. Divergent physiological and subjective responses to music interventions are common. The study by Radstaak et al. (2014) found that following a stress induction subjective recovery was greater for participants in a relaxing or happy self-selected music condition compared to participants in either a silent or active control condition, yet, physiological recovery (blood pressure and heart rate) was delayed in music listening conditions relative to control conditions. In contrast, Scheufele (2000) reported that compared to both a silent and active control condition levels of physiological recovery (heart rate) were greater in the music condition, but only a progressive muscle relaxation group reported subjective recovery from stress. Such studies highlight the relative independence between subjective and physiological outcomes relating to affective experience. 


\section{Music and Mindfulness}

As hypothesised, state mindfulness significantly increased for participants after listening to music, with large effect sizes. This supports one previous study finding increased mindfulness after listening to 30 minutes of researcher-selected music at home (Lynch \& Wilson, 2018). This is the first study to provide evidence that both self-selected and researcher-selected music listening can lead to increased levels of state mindfulness in the context of a stressful experience.

Consistent with research showing an association between mindfulness, regulation and stress reduction generally (Palmer \& Rodger, 2009; Regehr et al., 2013), there was a significant effect of mindfulness increase on state anxiety after listening to music. Specifically, in the selfselected music listening condition increasing mindfulness was associated with lower anxiety scores post-intervention. This same effect was not observed in the researcher-selected music condition. This finding suggests that in everyday settings where music listening is most often self-selected (Schäfer \& Sedmeier, 2009) mindfulness may play a part in musical affect regulation.

Higher scores on the State Mindfulness Scale represent an enhanced awareness of the inner experience, including noticing pleasant and unpleasant emotions and physical sensations (Tanay \& Bernstein, 2013). Considering mindfulness as a regulation strategy, it is conceptually distinct from distraction in the sense that it involves a direct focus on experience; and it may provide a counterforce to rumination in the sense that the focus of attention moves from one experience to the next rather than on sustained elaboration of ongoing thoughts, emotions, and sensations. Previous research outside the field of music research has also found mindfulness increase to be more effective for regulation than distraction and rumination (Broderick, 2005).

Baltazar and Saarikallio (2019) present a model describing a complex combination of the 
goals, strategies, and mechanisms involved in musical affect regulation. Among a number of other regulatory goals of music, they describe how people use music to engage in affective work by focusing on their feelings. Perhaps increased mindfulness and the associated focus on feelings and sensations provides a mechanism that supports affective work in music listening. At the same time, Baltazar and Saarikallio's model proposes that listeners can also use music to disengage from cognitions and affective states using strategies like distraction. Disengagement is achieved through mechanisms relating to features of the music (e.g., rhythmic entrainment). In the current study, the slow tempo music chosen by the researcher did not significantly reduce anxiety but did significantly increase mindfulness. At the same time, the positive relationship between increased mindfulness and reduced anxiety was significant in the self-selected music listening condition only. Future research is needed to examine the mechanisms of music-induced mindfulness, and to further clarify the role of mindfulness in musical affect regulation. Future studies could compare affect regulation following music listening alone, guided mindfulness induction, and music listening with a mindfulness induction against control conditions that limit or prevent mindfulness increase.

Research has shown that more frequent experiences of mindfulness is related to less stress, improved regulation, and increased wellbeing, and that mindfulness-based stress reduction interventions can reduce anxiety (Palmer \& Rodger, 2009; Regehr et al.,2013; Keng et al., 2011). The current research shows that a single session of music listening can increase self-reported mindfulness in a stressful situation, and that increased mindfulness predicted less anxiety after listening to self-selected music, suggesting that music listening may be a convenient and effective way of increasing mindfulness and coping with stress. An important aim for future research should be to examine the potential for music-based interventions to increase 
mindfulness and reduce stress and anxiety in the longer term.

\section{Limitations}

As is typical for studies employing university samples, both studies here had a greater proportion of female participants. While gender differences in stress, anxiety, cardiovascular reactivity and responses to music have been observed, findings are mixed (Steptoe, Fieldman, Evans \& Perry, 1996; Knight \& Rickard, 2001). Future studies should aim for an equal distribution, or consider recruiting only male or female participants to examine the effects of self-selected and researcherselected music on affect regulation in males and females. Further, participants were asked to refrain from smoking and caffeine intake prior to participating. Even so, participants' habitual use of nicotine and caffeine may have impacted physiological arousal in the current study (Childs \& de Wit, 2009), and therefore these behaviours should be controlled for in analyses. A great many studies have used the state-trait anxiety inventory to measure reactivity to and recovery from the TSST. However, additional measures of NA, such as Visual Analogue Scales, or the Perceived Stress Scale, in addition to a measure of anxiety could be very useful to include in future studies. The main focus of the current study was group differences in levels of NA after music listening versus a control, and the number of measurement points reflects that focus. However, to capture the dynamic nature of reactivity to stressors and responsivity to music listening interventions more measurements and longer intervals are needed in future studies.

\section{Conclusion}

These two studies provide evidence that a brief single session of music listening can reduce subjective feelings of anxiety in university students in preparation for a stressful situation, such as public speaking. Listening to music provided greater affect regulation than waiting in silence. However, listening to music may not have additional benefits over other activities in daily life 
(such as listening to a radio show) that also provide distraction or enjoyment. There was no effect of music on measures of physiological arousal. Music listening (self-selected or researcher-selected) significantly increased levels of mindfulness, and increased mindfulness predicted lower anxiety after self-selected music listening. Future research should explore the potential of music-based mindfulness interventions to reduce stress and anxiety. 


\section{References}

Augustine, A. A., \& Hemenover, S. H. (2009). On the relative effectiveness of affect regulation strategies: A meta-analysis. Cognition and Emotion, 23(6), 11811220.DOI:10.1080/02699930802396556

Baltazar, M., \& Saarikallio, S. (2019). Strategies and mechanisms in musical affect selfregulation: A new model. Musicae Scientiae, 23(2), 177-195. DOI: $10.1177 / 1029864917715061$

Birkett, M. A. (2011). The Trier Social Stress Test protocol for inducing psychological stress. Journal of Visualized Experiments, (56), e3238. DOI: 10.3791/3238

Broderick, P. C. (2005). Mindfulness and coping with dysphoric mood: Contrasts with rumination and distraction. Cognitive Therapy and Research, 29(5), 501-510. DOI:10.1007/s10608-005-3888-0

Burns, J., Labbé, E., Williams, K., \& McCall, J. (1999). Perceived and Physiological Indicators of Relaxation: As Different as Mozart and Alice in Chains. Applied Psychophysiology and Biofeedback, 24(3), 197-202. https://doi.org/10.1023/A:1023488614364

Chanda, M. L., \& Levitin, D. J. (2013). The neurochemistry of music. Trends in Cognitive Sciences, 17(4), 179-193. https://doi.org/10.1016/j.tics.2013.02.007.

Childs, E., \& de Wit, H. (2009). Hormonal, cardiovascular, and subjective responses to acute stress in smokers. Psychopharmacology, 203(1), 1. https://doi.org/10.1007/s00213-008$1359-5$

Cohen, S., \& Williamson, G. M. (1991). Stress and infectious disease in humans. Psychological Bulletin, 109(1), 5-24.http://dx.doi.org/10.1037/0033-2909.109.1.5 
de la Torre-Luque, A., Díaz-Piedra, C., \& Buela-Casal, G. (2017). Effects of preferred relaxing music after acute stress exposure: A randomized controlled trial. Psychology of Music, 45(6), 795-813. https://doi.org/10.1177/0305735617689953

Eerola, T., \& Vuoskoski, J. K. (2013). A review of music and emotion studies: Approaches, emotion models, and stimuli. Music Perception: An Interdisciplinary Journal, 30(3), 307-340. DOI:10.1525/MP.2012.30.3.307

Gabrielsson, A. (2010). Strong experiences with music. In P. N. Juslin \& J. A. Sloboda (Eds.), Handbook of music and emotion: Theory, research, applications (pp. 547-574). Oxford: Oxford University Press.

Goldin, P. R., \& Gross, J. J. (2010). Effects of mindfulness-based stress reduction (MBSR) on emotion regulation in social anxiety disorder. Emotion, 10(1), 83. DOI: $\underline{10.1037 / \mathrm{a} 0018441}$

Groarke, J. M., \& Hogan, M. J. (2018). Development and psychometric evaluation of the adaptive functions of music listening scale. Frontiers in Psychology, 9, 516. https://doi.org/10.3389/fpsyg.2018.00516

Hayes, A. F. (2017). Introduction to mediation, moderation, and conditional process analysis: A regression-based approach. Guilford Publications. ISBN: 9781462534654

Higher Education Authority (2018). Key facts and figures - Higher education 2017/18 (Annual Report No. 14). Retrieved from http://hea.ie/assets/uploads/2019/01/Higher-EducationAuthority-Key-Facts-Figures-2017-18.pdf

Iwanaga, M., \& Moroki, Y. (1999). Subjective and physiological responses to music stimuli controlled over activity and preference. Journal of Music Therapy, 36(1), 26-38. https://doi-org.queens.ezp1.qub.ac.uk/10.1093/jmt/36.1.26 
Juslin, P. N., \& Sloboda, J. A. (2001). Music and emotion: Theory and research. Oxford University Press.

Kabat-Zinn, J. (2003). Mindfulness-based interventions in context: past, present, and future. Clinical Psychology: Science and Practice, 10(2), 144-156 https://doi.org/10.1093/clipsy.bpg016

Keng, S. L., Smoski, M. J., \& Robins, C. J. (2011). Effects of mindfulness on psychological health: A review of empirical studies. Clinical Psychology Review, 31(6), 1041-1056. DOI: 10.1016/j.cpr.2011.04.006

Khalfa, S., Dalla Bella, S., Roy, M., Peretz, I., \& Lupien, S. J. (2003). Effects of relaxing music on salivary cortisol level after psychological stress. Annals of the New York Academy of Sciences, 999, 374-376. DOI:10.1196/annals.1284.045

Kirschbaum, C., Pirke, K. M., \& Hellhammer, D. H. (1993). The 'Trier Social Stress Test'-a tool for investigating psychobiological stress responses in a laboratory setting. Neuropsychobiology, 28(1-2), 76-81. DOI:10.1159/000119004

Knight, W. E., \& Rickard, N. S. (2001). Relaxing music prevents stress-induced increases in subjective anxiety, systolic blood pressure, and heart rate in healthy males and females. Journal of Music Therapy, 38(4), 254-272. https://doiorg.queens.ezp1.qub.ac.uk/10.1093/jmt/36.1.26

Lonsdale, A. J., \& North, A. C. (2011). Why do we listen to music? A uses and gratifications analysis. British Journal of Psychology, 102(1), 108-134. DOI: $10.1348 / 000712610 \times 506831$

Lynch, J., \& Wilson, C. E. (2018). Exploring the impact of choral singing on mindfulness. Psychology of Music, 46(6), 848-861. https://doi.org/10.1177/0305735617729452 
Nantais, K. M., \& Schellenberg, E. G. (1999). The Mozart effect: An artifact of preference. Psychological Science, 10(4), 370-373. https://doi.org/10.1111/1467$\underline{9280.00170}$

Nater, U. M., Abbruzzese, E., Krebs, M., \& Ehlert, U. (2006). Sex differences in emotional and psychophysiological responses to musical stimuli. International Journal of Psychophysiology, 62(2), 300-308. DOI:10.1016/j.ijpsycho.2006.05.011

Nolen-Hoeksema, S. (1991). Responses to depression and their effects on the duration of depressive episodes. Journal of Abnormal Psychology, 100(4), 569. DOI:10.1037//0021$\underline{843 x .100 .4 .569}$

North, A. C., \& Hargreaves, D. J. (2000). Musical preferences during and after relaxation and exercise. The American Journal of Psychology, 113(1), 43-67. DOI: 10.2307/1423460

North, A. C., Hargreaves, D. J., \& Hargreaves, J. J. (2004). Uses of music in everyday life. Music Perception: An Interdisciplinary Journal, 22(1), 41-77. DOI: $\underline{10.1525 / \mathrm{mp} .2004 .22 .1 .41}$

Palmer, A., \& Rodger, S. (2009). Mindfulness, stress, and coping among university students. Canadian Journal of Counselling, 43, 198-212. Retrieved from https://cjc$\underline{\text { rcc.ucalgary.ca/article/view/59019 }}$

Panteleeva, Y., Ceschi, G., Glowinski, D., Courvoisier, D. S., \& Grandjean, D. (2017). Music for anxiety? Meta-analysis of anxiety reduction in non-clinical samples. Psychology of Music, 46(4), 473-487. https://doi.org/10.1177/0305735617712424

Pelletier, C. L. (2004). The effect of music on decreasing arousal due to stress: A metaanalysis. Journal of Music Therapy, 41(3), 192-214. https://doiorg.queens.ezp1.qub.ac.uk/10.1093/jmt/41.3.192 
Radstaak, M., Geurts, S. A. E., Brosschot, J. F., \& Kompier, M. A. J. (2014). Music and Psychophysiological Recovery from Stress. Psychosomatic Medicine, 76(7), 529537.DOI: 10.1097/PSY.0000000000000094.

Rauscher, F. H., Shaw, G. L., \& Ky, K. N. (1993). Music and spatial task performance. Nature, 365(6447), 611. DOI: 10.1038/365611a0

Regehr, C., Glancy, D., \& Pitts, A. (2013). Interventions to reduce stress in university students: A review and meta-analysis. Journal of Affective Disorders, 148(1), 1-11.DOI: 10.1016/j.jad.2012.11.02

Russell, J. A. (1980). A circumplex model of affect. Journal of Personality and Social Psychology, 39(6), 1161-1178. DOI: 10.1037/h0077714

Sandstrom, G. M., \& Russo, F. A. (2010). Music hath charms: The effects of valence and arousal on recovery following an acute stressor. Music and Medicine, 2(3), 137143. ISSN:1943-8621

Schäfer, T., \& Sedlmeier, P. (2009). From the functions of music to music preference. Psychology of Music, 37(3), 279-300. DOI: 10.1177/0305735608097247

Scherer, K. R. (1984). Emotion as a multicomponent process: A model and some cross-cultural data. In P. Shaver (Ed.), Review of personality and social psychology (Vol. 5, pp. 37-63). Beverly Hills, CA: Sage. https://doi.org/10.1177/0539018405058216

Scheufele, P. M. (2000). Effects of progressive relaxation and classical music on measurements of attention, relaxation, and stress responses. Journal of Behavioral Medicine, 23(2), 207-228. https://doi.org/10.1023/A:1005542121935

Sharman, L., \& Dingle, G. (2015). Extreme Metal Music and Anger Processing. Frontiers in Human Neuroscience, 9, 960. https://doi.org/10.3389/fnhum.2015.00272 
Sleigh, M. J., \& McElroy, J. (2014). The effect of music listening versus written reframing on mood management. Music Perception: An Interdisciplinary Journal, 31(4), 303-287 315. DOI: $10.1525 / \mathrm{mp} .2014 .31 .4 .303$

Spielberger, C. D., Gorsuch, R. L., Lushene, R. E., \& Vagg, P. R. (2010). State-trait anxiety inventory (STAI). BiB, 1970, 180.

Steptoe, A., Fieldman, G., Evans, O., \& Perry, L. (1996). Cardiovascular risk and responsivity to mental stress: the influence of age, gender and risk factors. Journal of Cardiovascular Risk, 3(1), 83-93. DOI: 10.1177/174182679600300112

Tanay, G., \& Bernstein, A. (2013). State Mindfulness Scale (SMS): development and initial validation. Psychological Assessment, 25(4), 1286. DOI: 10.1037/a0034044

Thaut, M. H., \& Davis, W. B. (1993). The influence of subject-selected versus experimenterchosen music on affect, anxiety, and relaxation. Journal of Music Therapy, 30(4), 210223. http://dx.doi.org/10.1093/jmt/30.4.210

van Goethem, A., \& Sloboda, J. (2011). The functions of music for affect regulation. Musicae Scientiae, 15(2), 208-228. DOI: 10.1177/1029864911401174 
Table 1. Participant Characteristics, Means and SD of State Anxiety, Systolic Blood Pressure (SBP), and Diastolic Blood Pressure (DBP) at Baseline, Post-induction, and Post-intervention for Study 1.

\begin{tabular}{|c|c|c|c|c|c|c|c|c|c|}
\hline & Control & Researcher- & Self- & Control & Researcher- & Self- & Control & Researcher- & Self-Selected \\
\hline & Group & Selected & Selected & Group & Selected & Selected & Group & Selected & \\
\hline \multirow[t]{4}{*}{ Participants } & $\mathrm{N}=23$ & $\mathrm{~N}=23$ & $\mathrm{~N}=24$ & $18-53$ years & $18-27$ years & $17-35$ years & $M=20.50$ & $M=20.20$ & $M=20.70$ \\
\hline & (7 males) & (6 males) & (4 males) & & & & $S D=7.20$ & $S D=2.50$ & $S D=3.60$ \\
\hline & \multicolumn{3}{|c|}{ Baseline } & \multicolumn{3}{|c|}{ Post-induction } & \multicolumn{3}{|c|}{ Post-intervention } \\
\hline & $M e a n \pm S D$ & $M e a n \pm S D$ & $M e a n \pm S D$ & $M e a n \pm S D$ & $M e a n \pm S D$ & $M e a n \pm S D$ & $M e a n \pm S D$ & $M e a n \pm S D$ & $M e a n \pm S D$ \\
\hline Anxiety & $34.26 \pm 10.20$ & $33.30 \pm 7.63$ & $35.46 \pm 8.61$ & $46.29 \pm 11.10$ & $45.22 \pm 11.23$ & $47.58 \pm 10.38$ & $42.17 \pm 11.51$ & $34.35 \pm 7.74$ & $33.54 \pm 8.53$ \\
\hline SBP & $120.13 \pm 12.20$ & $119.56 \pm 15.16$ & $119.08 \pm 10.17$ & $118.13 \pm 10.04$ & $117.13 \pm 11.79$ & $115.79 \pm 8.66$ & $117.09 \pm 9.77$ & $113.70 \pm 13.47$ & $115.12 \pm 14.84$ \\
\hline DBP & $66.83 \pm 7.06$ & $66.78 \pm 7.90$ & $68.78 \pm 10.79$ & $67.5 \pm 7.8$ & $68.30 \pm 6.23$ & $67.96 \pm 5.99$ & $68.26 \pm 6.20$ & $68.17 \pm 9.52$ & $68.44 \pm 5.66$ \\
\hline
\end{tabular}


Table 2. Participant Characteristics, Means and SD of State Anxiety, Systolic Blood Pressure (SBP), Diastolic Blood Pressure (DBP), and State

Mindfulness at baseline, post-induction, and post-intervention for Study 2.

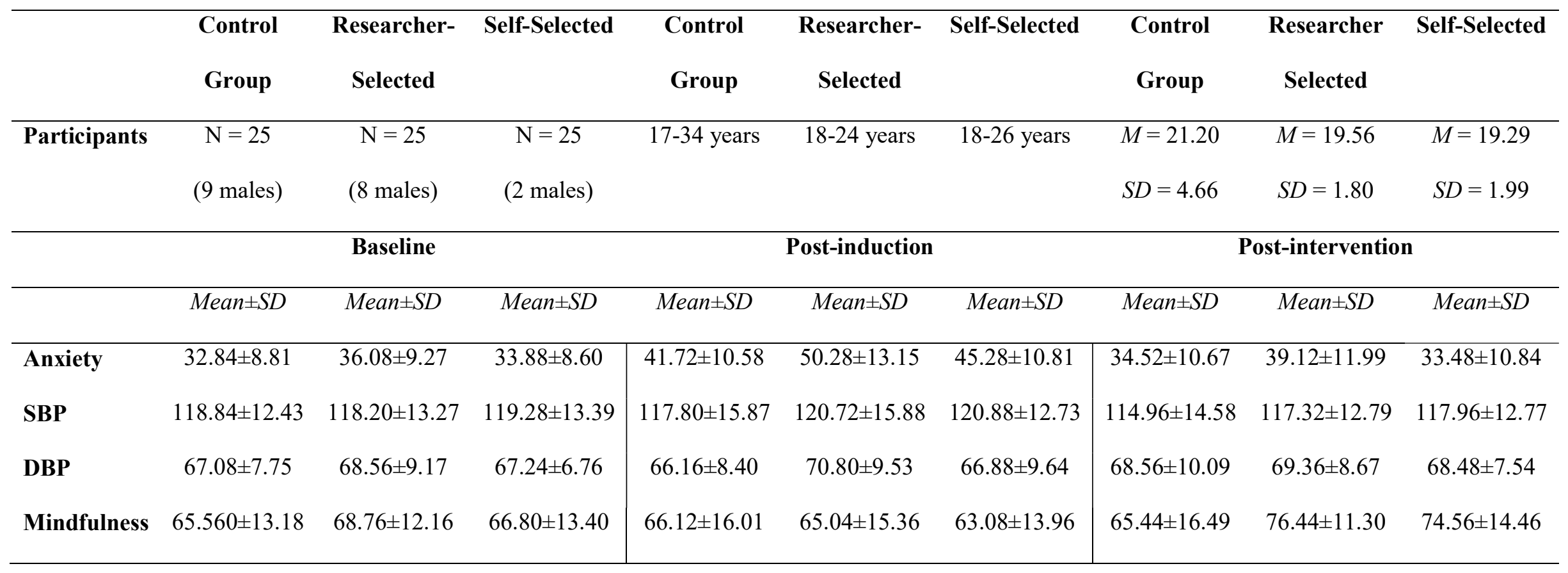

